\title{
Radiocarbon Evidence for Decomposition of Aged Organic Matter in the Vadose Zone as the Main Source of Speleothem Carbon
}

\author{
Alexandra L Noronha ${ }^{a, 1, *}$, Kathleen R Johnson ${ }^{\mathrm{a}}$, John R Southon ${ }^{\mathrm{a}}$, \\ Chaoyang $\mathrm{Hu}^{\mathrm{b}}$, Jiaoyang Ruan ${ }^{\mathrm{b}, 2}$, Staryl McCabe-Glynn ${ }^{\mathrm{a}}$ \\ ${ }^{a}$ Department of Earth System Science, University of California, Irvine, 92697, USA \\ ${ }^{b}$ State Key Laboratory of Biogeology and Environmental Geology, China University of \\ Geosciences, Wuhan, 430074, PR China
}

\begin{abstract}
Several recent studies have used records of the radiocarbon $\left({ }^{14} \mathrm{C}\right)$ bomb peak in speleothems to inversely model the soil $a^{14} \mathrm{CO}_{2}$ and the age distribution of soil organic material (SOM) above caves, in part to investigate the potential of speleothems as sensitive records of past SOM dynamics. The results of these modeling studies have suggested that soil $\mathrm{CO}_{2}$ at karst sites is derived primarily from the decomposition of SOM with turnover times on the order of decades to centuries. This result is in stark contrast with observations of soil $a^{14} \mathrm{CO}_{2}$ at non-karst sites, which indicate that soil $\mathrm{CO}_{2}$ is derived primarily from root respiration and decomposition of SOM with much shorter turnover times. This discrepancy suggests that SOM in karst settings may have a very different age distribution than sites that have been studied previously and/or that soil $\mathrm{CO}_{2}$ is not the main source of speleothem carbon. To
\end{abstract}

\footnotetext{
*Corresponding author: anoronha@uci.edu

${ }^{1}$ Now at, Jackson School of Geosciences, University of Texas at Austin, 78712, USA

${ }^{2}$ Now at, Laboratoire des Sciences du Climat et de l'Environnement (LSCE), CNRS/CEA/UVSQ, L'Orme des Merisiers, 91191 Gif-sur-Yvette Cedex, France
} 
help resolve this discrepancy, we present an improved inverse model which we use to estimate the age of $\mathrm{CO}_{2}$ above several caves. We also present results from a detailed case study of soil carbon dynamics at Heshang Cave, China. This work demonstrates that SOM in karst sites may be much older than $\mathrm{SOM}$ in non-karst soils that have been studied previously, but that $\mathrm{CO}_{2}$ produced in the shallow soil zone is unlikely to be the main source of speleothem carbon. A review of the literature suggests that the most likely explanation for the aforementioned discrepancy is that decomposition of down-washed $\mathrm{SOM}$ in the vadose zone is the dominant source of speleothem carbon.

Keywords:

speleothems, carbon cycle, radiocarbon, soil carbon, carbon isotopes

1. Introduction

Speleothem calcite carbon isotope records contain valuable paleoenviron3 mental information, but are largely under-exploited as interpretation of these 4 records has proved challenging due to the potential for large variations in the 5 carbon isotope ratio of the source material, as well as the numerous processes during dissolution and precipitation of calcite which alter carbon isotope ratios. While much work has been done to understand the physical and chemical controls on speleothem carbon isotope ratios (e.g. Hendy, 1971; Genty et al., 2001; Mickler et al., 2004; Spötl et al., 2005; Fairchild et al., 2006; Dreybrodt, 2008; Frisia et al., 2011), the basic conceptual model of the sources of speleothem carbon which suggests that it is derived from two main sources - soil $\mathrm{CO}_{2}$ and carbonate bedrock - has remained largely unchanged. Given the large difference between carbon isotope ratios of soil $\mathrm{CO}_{2}\left(\delta^{13} \mathrm{C}\right.$ 
14

$\approx-10$ to $\left.-27 \%, a^{14} \mathrm{C} \geq 100 \mathrm{pMC}\right)$ and carbonate bedrock $\left(\delta^{13} \mathrm{C} \approx 0 \%, a^{14} \mathrm{C}\right.$ $=0 \mathrm{pMC}$ ), where carbonate dissolution occurs along the soil to bedrock profile is the one of the most important factors in determining dripwater dissolved inorganic carbon (DIC) isotope ratios. If carbonate dissolution occurs in the soil zone where water is simultaneously in contact with both soil $\mathrm{CO}_{2}$ and carbonates in the soil, continuous equilibration between soil water DIC and soil $\mathrm{CO}_{2}$ occurs during carbonate dissolution. In this scenario, which is referred to as open-system dissolution, DIC isotope ratios are determined by the soil $\mathrm{CO}_{2}$ isotope ratios. In the alternative scenario, closed-system dissolution, carbonate dissolution does not begin until waters that have equilibrated with soil $\mathrm{CO}_{2}$ enter the pore space and fractures of the carbonate bedrock where carbonate dissolution occurs isolated from $\mathrm{CO}_{2}$. Closed-system dissolution leads to a DIC isotope ratio determined by an approximately $50 / 50$ mixture of soil $\mathrm{CO}_{2}$ and carbonate bedrock, as reaction stoichiometry dictates that dissolution of one mole of $\mathrm{CaCO}_{3}$ is necessary to neutralize one mole of dissolved $\mathrm{CO}_{2}$ (Hendy, 1971). In natural systems carbonate dissolution usually falls somewhere between the two end member scenarios.

Measurements of $a^{14} \mathrm{C}$ are reported corrected for isotope fractionation (Stuiver and Polach, 1977), allowing for interpretation of speleothem $a^{14} \mathrm{C}$ as a reflection of only the carbonate dissolution regime and the soil $a^{14} \mathrm{CO}_{2}$. Soil $\mathrm{CO}_{2}$ is a mixture of atmospheric $\mathrm{CO}_{2}, \mathrm{CO}_{2}$ produced by root respiration, and $\mathrm{CO}_{2}$ produced by decomposition of aged soil organic matter (SOM). Therefore speleothem calcite $a^{14} \mathrm{C}$ is affected by the decomposition of aged SOM and is influenced by changes in SOM dynamics. Under the assumption the carbonate dissolution regime at a site can be taken to be 
relatively invariable over the twentieth century, several recent studies have interpreted speleothem-based $a^{14} \mathrm{C}$ records of the twentieth century atmospheric $a^{14} \mathrm{C}$ bomb peak as records of soil $a^{14} \mathrm{CO}_{2}$ (e.g. Genty and Massault, 1999; Fohlmeister et al., 2010; Fohlmeister et al., 2011a; Griffiths et al., 2012; and Rudzka-Phillips et al., 2013). These studies have employed a simple soil carbon model to inversely model the age distribution of SOM at karst sites using speleothem $a^{14} \mathrm{C}$ bomb peak records, in part to investigate the potential of speleothems as sensitive recorders of past soil carbon dynamics.

The results of these studies have suggested that karst soil $\mathrm{CO}_{2}$ has prebomb mean ages ranging from 42-488 years. These predictions are at odds with observations of soil $\mathrm{CO}_{2}$ ages in non-karst sites, which are typically on the order of years, with $\mathrm{CO}_{2}$ derived from root respiration and decomposition of organic matter with a turnover time of $<1$ yr comprising 50-60\% of soil $\mathrm{CO}_{2}$ in boreal and temperate sites and $>80 \%$ in tropical sites (Trumbore, 2000). To date there is only one published measurement of soil $a^{14} \mathrm{CO}_{2}$ in karst terrain, from Cave of the Bells, Arizona, which was indistinguishable from contemporaneous atmospheric $a^{14} \mathrm{CO}_{2}$ (Breecker et al., 2012). This discrepancy between observed soil $\mathrm{CO}_{2}$ ages and the predicted mean age of soil $\mathrm{CO}_{2}$ in karst settings based on the shape of the bomb peak in speleothems suggests that:

1. soil carbon dynamics in karst settings may be very different than those in sites that have been studied previously and/or

2. soil $\mathrm{CO}_{2}$ is not the main source of speleothem carbon.

Both of these hypotheses have major implications for interpretation of speleothem $\delta^{13} \mathrm{C}$ and $a^{14} \mathrm{C}$ records, as well as for understanding the role of karst soils in 
the global carbon cycle.

This study seeks to resolve the cause of the discrepancy between observations of soil $\mathrm{CO}_{2}$ and speleothem bomb peak records through observations of soil $\delta^{13} \mathrm{C}$ and $a^{14} \mathrm{C}$ in Heshang Cave, China. This work presents a new bomb peak record from speleothem HS4 from Heshang Cave, China and a geochemical box model that builds on previous attempts to infer the age of the source of speleothem carbon. This model is used to evaluate the age spectrum of SOM required to produce the speleothem bomb peak at HS4 and 13 other speleothem bomb peak records in the literature (Table 1).

\section{Site and sample description}

Heshang Cave is located in the Hubei Provence of China $\left(30.44^{\circ} \mathrm{N}, 110.42^{\circ} \mathrm{E}\right.$, $294 \mathrm{~m}$ asl), $\sim 100 \mathrm{~km}$ west of the city of Yichang in the middle reaches of the Yangtze Valley. The cave is $250 \mathrm{~m}$ long, roughly horizontal, and overlain with $\sim 400 \mathrm{~m}$ of Cambrian dolomite. The hillside has a very thin soil cover of 5-30 cm of well-developed soil derived from dolomite bedrock, wind-blown silicate dust, and organic matter from the dense local vegetation. The cave has a large entrance with a height of about $20 \mathrm{~m}$ and is well ventilated. Annual average temperature in the study area is $\sim 18^{\circ} \mathrm{C}$, with daily averages ranging from $5^{\circ} \mathrm{C}$ to $28^{\circ} \mathrm{C}$. Unlike many caves, cave temperature at Heshang Cave exhibits a seasonal cycle, ranging from $16^{\circ} \mathrm{C}$ to $22^{\circ} \mathrm{C}$, lagging the local temperature cycle by 2-3 months (Johnson et al., 2006).

HS4 is a $2.5 \mathrm{~m}$ long annually banded stalagmite that was actively forming when it was collected from Heshang Cave in 2001. The HS4 site is located $\sim 150 \mathrm{~m}$ from the entrance of the cave, and was still actively dripping 
when this study was undertaken. Records of $\delta^{18} \mathrm{O}, \delta^{13} \mathrm{C}$, and $a^{14} \mathrm{C}$ covering the Holocene measured on HS4 have been previously reported by $\mathrm{Hu}$ et al. (2008b), Liu et al. (2013), and Noronha et al. (2014). The age model for the final 150 years of stalagmite growth is well-defined by annual layer counting (Hu et al., 2008b). Average transit time of water from the infiltration zone to the drip site at HS4 has been shown to be $<1$ yr based on the seasonal cycle of drip water $\delta^{18} \mathrm{O}$ (Johnson et al., 2006).

\section{Methods}

\subsection{Speleothem calcite}

The stalagmite, HS4, was previously cut in half parallel to the growth axis and the surface was polished to reveal laminations consisting of sub-mm scale light and dark couplets, which has been shown to be annual (Hu et al., 2008b). HS4 calcite is milky, opaque, and porous, with a fabric dominantly characterized as open columnar using the terminology of Frisia and Borsato (2010). Speleothem calcite for the twentieth century record of $a^{14} \mathrm{C}$ was drilled parallel to growth lamina as powder using a New Wave Research micromill. The age model for the twentieth century is based on annual layer counting described in $\mathrm{Hu}$ et al. (2008a).

Speleothem calcite samples were pretreated with a $10 \% \mathrm{HCl}$ leach, and subsequently hydrolyzed in $85 \% \mathrm{H}_{3} \mathrm{PO}_{4}$. After conversion to $\mathrm{CO}_{2}$, calcite samples were converted to graphite via iron catalyzed hydrogen reduction following standard protocols as described in Santos et al. (2007). 


\subsection{Soil organic matter}

Because access to the recharge zone is difficult, all soil sampling was conducted at a site near the entrance of the cave. One expedition to the recharge zone in August 2004 described the soil at the recharge zone as $30 \mathrm{~cm}$ deep with reasonably dense vegetation (Hu et al., 2008a), which is consistent with the site at which sampling was conducted. Soil was collected from a site near the cave entrance during the field trip in March 2010 in 5 cm depth intervals until the bedrock was reached. Prior to measurement, visible roots were picked out and soil samples were dried in an oven at $65^{\circ} \mathrm{C}$ for $12-24$ hrs.

SOM was analyzed for $a^{14} \mathrm{C}$ and $\delta^{13} \mathrm{C}$ in both bulk and size fractionated form. Size fractions used are defined as coarse sand $(>425 \mu \mathrm{m})$, medium sand $(425-250 \mu \mathrm{m})$, fine sand $(250-63 \mu \mathrm{m})$, and silt and clay $(<63 \mu \mathrm{m})$. All SOM samples were ground to powder because of the presence of dolomite, which is more resistant to acid hydrolysis than calcite. Soil samples were acidified with $1 \mathrm{~N} \mathrm{HCl}$ overnight to remove carbonate. Following acidification, SOM samples were converted to $\mathrm{CO}_{2}$ via combustion in evacuated sealed quartz tubes at $900{ }^{\circ} \mathrm{C}$ for $3.5 \mathrm{hrs}$, cryogenically purified, and graphitized via hydrogen reduction.

\subsection{Soil $\mathrm{CO}_{2}$}

Soil $\mathrm{CO}_{2}$ from depth was sampled using stainless steel gas wells, which were installed in the soil at a variety of depths. $\mathrm{CO}_{2}$ was sampled 12-24 hrs after installation of wells, and wells removed at the end of each field trip. Wells were flushed with soil gas following installation. $p \mathrm{CO}_{2}$ was measured with a portable infra-red gas analyzer (LI-820 $\mathrm{CO}_{2}$ Analyzer, LICOR Inc., 
Lincoln, NE, USA). When $p \mathrm{CO}_{2}$ was above 2,000 ppm sample was collected in $0.5 \mathrm{~L}$ evacuated stainless steel canisters to achieve the in desired sample size of $\sim 1 \mathrm{mg}$ carbon. When sampling with stainless steel canisters, flow was restricted by stainless steel capillary $(0.010 \mathrm{~cm} \times 0.063 \mathrm{~cm} \times 30 \mathrm{~cm}$, Fisher $)$. When $p \mathrm{CO}_{2}$ was below 2,000 ppm, samples were collected by pumping for $\sim 15$ minutes through steel traps containing activated molecular sieves $(13 \times$ powder-free 133 8/12 beads, Grace) using a diaphragm pump (Hargraves Fluidics BTC Series miniature). The very large sample volumes necessary, especially when pumping was required, render the samples representative of a depth integrated average instead of representative of the depth at which they were collected. Samples were filtered through Drierite desiccant (W.A. Hammond Drierite Co. Ltd., Xenia, OH, USA), and flow rate was measured as $1 \mathrm{~L} / \mathrm{min}$. One sample of atmospheric $\mathrm{CO}_{2}$ was collected in a steel trap at the cave site during the field trip in March 2010. To prevent $a^{14} \mathrm{C}$ memory effects traps were pre-conditioned by baking at $630{ }^{\circ} \mathrm{C}$ for 45 mins under vacuum.

Soil $\mathrm{CO}_{2}$ samples collected in evacuated flasks were extracted on line, and $\mathrm{CO}_{2}$ collected in steel traps was released for isotopic analysis by baking the traps at $475^{\circ} \mathrm{C}$. All $\mathrm{CO}_{2}$ samples were cryogenically purified and converted to graphite via the sealed tube zinc reduction method (Xu et al., 2007).

\subsection{Tree ring record of atmospheric $a^{14} C$}

A pine tree of unknown species from a location across the river from Heshang Cave was felled in July 2011 to create a record of local atmospheric $a^{14} \mathrm{C}$. A tree that was located $\sim 50 \mathrm{~m}$ away from a low traffic road was selected to avoid bias from point sources of fossil fuels. The 25 rings were assumed 
to be annual, and were counted to create a calendar age model for a record of local atmospheric $a^{14} \mathrm{C}$. The tree appeared to be colonized by blue-stain fungus, but a study by English et al. (2011) showed that blue-stain fungus colonization did not detectably alter whole wood or $\alpha$-cellulose $\delta^{18} \mathrm{O}$ or $\delta^{13} \mathrm{C}$, suggesting that translocation effects are minimal. The tree was sampled at an annual resolution, and pretreated to $\alpha$-cellulose using the methods described in Southon and Magana (2010). Briefly, 30 mg of shaved wood was treated with a standard acid-base-acid treatment, followed by a bleaching treatment to isolate hollocellulose, and a strong base treatment to isolate $\alpha$-cellulose. All samples were treated in individual $13 \mathrm{~mm}$ glass test tubes.

Tree cellulose was converted to $\mathrm{CO}_{2}$ via combustion in evacuated sealed quartz tubes at $900{ }^{\circ} \mathrm{C}$ for $3.5 \mathrm{hrs}$, cryogenically purified, and graphitized by iron catalyzed hydrogen reduction.

\subsection{Isotope analysis}

After conversion to graphite, all $a^{14} \mathrm{C}$ measurements were made at University of California Irvine on a NEC Compact (1.5 SDH) AMS system, using six aliquots of Oxalic Acid I as the normalizing standard. Each mg-sized carbon sample was measured multiple times (typically 8 to 15 runs) over a 24 hr period.

$\delta^{13} \mathrm{C}$ were measured by isotope ratio mass spectrometry at University of California, Irvine. Measurements on samples collected as gas were made on splits of $\mathrm{CO}_{2}$ injected into He-filled vials to a target concentration of 3,500 ppm $\mathrm{CO}_{2}$ using a Thermo Finnigan DeltaPlus equipped with a GasBench II autosampler. $\delta^{13} \mathrm{C}$ measurements on SOM were made by placing acidified, ground soil in tin capsules that are combusted to $\mathrm{CO}_{2}$ and analyzed by 


\subsection{Soil Carbon Model}

Previous attempts to evaluate the age distribution of soil carbon above caves using speleothem bomb peak records (e.g. Genty and Massault, 1999; Fohlmeister et al., 2010; Fohlmeister et al., 2011a; Griffiths et al., 2012; and Rudzka-Phillips et al., 2013) estimated the radiocarbon activity of soil $\mathrm{CO}_{2}\left(a^{14} C_{g}\right)$ using the equations originally proposed by Genty and Massault (1999):

$$
a^{14} C_{g}=C_{1}\left(a^{14} C_{a t m-y_{1}}\right)+C_{2}\left(a^{14} C_{a t m-y_{2}}\right)+C_{3}\left(a^{14} C_{a t m-y_{3}}\right)
$$

where $\mathrm{C}_{1}, \mathrm{C}_{2}$, and $\mathrm{C}_{3}$ are the relative proportion of three SOM pools such that:

$$
C_{1}+C_{2}+C_{3}=1
$$

and the $a^{14} \mathrm{C}_{a t m-y_{j}}$ is the $a^{14} \mathrm{C}$ of the pool approximated by a moving average, with a window, y, equal to the turnover time of the SOM pool:

$$
a^{14} C_{a t m-y}=\frac{\sum_{i=1}^{y} a^{14} C_{a t m_{i}}}{y}
$$

Approximating SOM $a^{14} \mathrm{C}$ via moving average results in modeling SOM pools as heterogenous, and decomposition of SOM as a zero-order process. That is, a moving average assumes the inputs to the SOM pool from each year contribute a constant and equal mass to the soil $\mathrm{CO}_{2}$ at every time step until the inputs are exhausted after y time steps. This deviates from typical 
geochemical box modeling approaches, where SOM within a given pool is homogenized, and the homogenized pool decomposes as a first-order process (Six and Jastrow, 2002). Additionally, these models did not include a pool with a turnover time of one year, essentially allowing for the possibility of soils where no root respiration or mixing with atmospheric $\mathrm{CO}_{2}$ was occurring.

Accordingly this study builds on these previous works by modeling SOM using a more typical geochemical box modeling approach with a total of 4 boxes - 3 homogenous SOM pools which decompose as a first-order process, and a pool with a turnover time $(\tau)$ equal to one year which represents root respiration, decomposition of organic matter of annual age, and any contribution from atmospheric $\mathrm{CO}_{2}$. This model is based on the steadystate time dependent model presented by Trumbore (1993) and described in detail by Gaudinski et al. (2000). The model is implemented using the Matlab Global Optimization solver tool, MultiStart, to generate 1,000 sets of random start points for the parameters $\mathrm{P}_{j}$ and $\tau_{j}$, where $\mathrm{j}=1: 4$ and $\mathrm{P}_{j}$ represents the relative proportions of four SOM pools, and $\tau_{j}$ is the associated turnover time for each SOM pool. The parameters $\mathrm{P}_{j}$ are constrained to satisfy the requirements, $\sum P_{j}=1$ and $0<P_{j}<1$. The first pool is fixed as an annual pool (i.e. $\tau_{1}=1$ ), and the rest of the pools are constrained to represent pools with turnover times on the order of years to decades, centuries, and millennia (i.e. $1<\tau_{2}<100 ; 100<\tau_{3}<1$, 000; $1,000<\tau_{4}<$ 10,000). The model is initialized by starting calculations 100 years before the year of deposition of the first speleothem $a^{14} \mathrm{C}$ measurement, and setting the initial $a^{14} \mathrm{C}$ of each SOM pool equal to the average of the decay corrected $a^{14} \mathrm{C}$ of the atmosphere over the last $\tau$ years. 
These parameters $\left(\mathrm{P}_{j}\right)$ are taken to represent the relative proportions and turnover times of SOM pools, and the relative proportion of the soil $\mathrm{CO}_{2}$ fluxes are derived from them, instead of estimating the relative proportions of SOM contributions to the soil $\mathrm{CO}_{2}$ directly. This distinction is highlighted because, in part due to the use of the moving average approach to estimating $a^{14} \mathrm{C}$ of SOM pools, the language in previous studies was ambiguous and at times erroneously implied that the contribution of a SOM pool to the total amount of SOM is equal to the contribution of $\mathrm{CO}_{2}$ of that pool to the soil $\mathrm{CO}_{2}$ e.g. in a soil that is a 50/50 mixture of SOM pools with $\tau=5 \mathrm{yr}$ and $\tau=100 \mathrm{yr}$, both pools are assumed to produce the same mass of $\mathrm{CO}_{2}$. In reality, at steady state, making the assumption that the only loss pathway for a $\mathrm{SOM}$ is decomposition, the size of a flux of $\mathrm{CO}_{2}$ from a SOM pool is a function of its turnover time $\tau$ :

$$
F=\frac{M}{\tau}
$$

where $\mathrm{F}$ is the flux from a pool, and $\mathrm{M}$ is the mass of the pool. Therefore the steady state loss of the pool with $\tau=5 \mathrm{yr}$ will be $1 / 5$ of its mass, and the steady state loss of the pool with $\tau=100 \mathrm{yr}$ with be $1 / 100$ of its mass, meaning that the flux from the pool with a $\tau$ of 5 years will make up $95 \%$ of the soil $\mathrm{CO}_{2}$. In this manuscript, the relative parameters representing the proportions of the $\mathrm{CO}_{2}$ fluxes are referred to as $\mathrm{F}_{j}$.

After calculating the steady state fluxes from the SOM pools and their relative contributions to the $\mathrm{CO}_{2}$, the $a^{14} \mathrm{C}$ of the $\mathrm{SOM}$ pool at each time step is calculated via:

$$
a^{14} C_{j_{y_{i}}}=a^{14} C_{j_{y_{i-1}}}\left(1-\frac{1}{\tau_{j}}\right)\left(e^{-\lambda}\right)+a^{14} C_{a t m_{y_{i}}}\left(\frac{1}{\tau_{j}}\right)
$$


where $i$ is the current model step year and $j$ refers to the SOM pool 1-4, and $\lambda$ is radiocarbon decay constant using a 5,370 yr half life. The inputs to all pools have the $a^{14} \mathrm{C}$ of the atmosphere at the given model step year $\left(a^{14} C_{a t m_{y_{i}}}\right)$.

Fluxes are then multiplied by the $a^{14} \mathrm{C}$ of the pools at the model step and summed together to find the $a^{14} \mathrm{CO}_{2}$ at the model step:

$$
a^{14} C O_{2\left(y_{i}\right)}=\sum_{j=1}^{4} F_{j}\left(a^{14} C_{j_{y_{i}}}\right)
$$

Once the entire twentieth century soil $a^{14} \mathrm{CO}_{2}$ record is calculated from the start points generated, the offset between the pre-bomb interval $(y<1955)$ of the calculated curve to the measured speleothem bomb peak curve to estimate the contribution from ${ }^{14} \mathrm{C}$-free sources is found, and this difference is subtracted from the entire curve. After this step, the residuals are computed and using the Matlab optimization function, fmincon, the parameters that yield the best fit with the measured speleothem bomb peak is iteratively calculated from each set of start points.

Atmospheric $a^{14} \mathrm{C}$ used in the model for the post-bomb era is based on the Hua et al. (2013) reconstructions of regional atmospheric $a^{14} \mathrm{C}$ at annual resolution, and values for the pre-bomb era are based on linear interpolation of the IntCal13 Northern and Southern Hemisphere curves to annual resolution (Reimer et al., 2013). In addition to modeling the soil gas age at the infiltration site for HS4, the model is applied to 13 speleothem bomb peak records (shown in Table 1) from the literature that have published age models which are based on independent methods, i.e. adjustments to age models and speleothems with age models based $a^{14} \mathrm{C}$ bomb peak evidence 
are excluded.

In contrast to some previous models, fractionation effects are not considered in these calculations. Because these models do not consider temperature, fractionation affects all time steps by the same constant term. Therefore ignoring fractionation does not affect the shape of the bomb peak curve generated by the model, only the contribution of aged carbon from dead sources. Additionally, it is worth noting that there has been significant confusion in the speleothem literature recently about the correct formulae to correct for fractionation. Several speleothem geochemical modeling studies have used a value of 2.3 for fractionation changes in ${ }^{14} \mathrm{C} /{ }^{12} \mathrm{C}$ vs. ${ }^{13} \mathrm{C} /{ }^{12} \mathrm{C}$ based on an attempt to determine the fractionation of ${ }^{14} \mathrm{C}$ relative to ${ }^{13} \mathrm{C}$ in photosynthesis (Saliege and Fontes, 1984). The experiment was probably compromised by contributions of fossil fuel and the value of 2.3 has no support from quantum theory (Southon, 2011).

\section{Results}

\subsection{Measurements}

The results of the tree ring record of local atmospheric $a^{14} \mathrm{C}$ and the single measurement of atmospheric $a^{14} \mathrm{CO}_{2}$ are shown in Figure 1 and suggest that atmospheric $a^{14} \mathrm{C}$ at the study site is similar to, though slightly lower than, the regional atmospheric $a^{14} \mathrm{C}$ as approximated by the Northern Hemisphere zone 3 reconstruction from Hua et al. (2013). There appears to be an increasing divergence with time between the tree ring record and the Northern Hemisphere zone 3 reconstruction, which is probably a regional offset due to the rapid increase in emission of ${ }^{14} \mathrm{C}$-free fossil fuel derived $\mathrm{CO}_{2}$ in China 
Table 1: Speleothem bomb peak records referred to in this text. Modified from Table 1 in Rudzka-Phillips et al., 2013

\begin{tabular}{ll}
\hline Speleothem & reference \\
\hline Asfa-3 & Baker et al., 2007 \\
CC-Bil & Rudzka-Phillips et al., 2013 \\
ER-77 & Fohlmeister et al., 2011a \\
Fau-stm14 & Genty and Massault, 1999 \\
GAR-02 & Rudzka-Phillips et al., 2013 \\
Gib04a & Mattey et al., 2008 \\
Han-stm5 & Genty et al., 1998 \\
HS4 & this publication \\
LR06-B1 & Griffiths et al., 2012 \\
Merc-1 & Baker et al., 2007 \\
Obi84 & Smith et al., 2009 \\
Pos-stm4 & Genty et al., 1998 \\
So-11 & Rudzka-Phillips et al., 2013 \\
T7 & Sundqvist et al., 2013 \\
\hline
\end{tabular}

during the beginning of the 21st century. Given the good agreement between the tree ring record and the Northern Hemisphere zone 3 reconstruction before $2000 \mathrm{AD}$, the Northern Hemisphere zone 3 reconstruction is considered to be an appropriate approximation of atmospheric $a^{14} \mathrm{CO}_{2}$ at Heshang Cave for the use in the soil carbon model.

HS4 speleothem calcite $a^{14} \mathrm{C}$ begins to increase in response to the atmospheric $a^{14} \mathrm{C}$ bomb peak by 1959 from the pre-bomb average value of 
$88.30 \pm 0.18 \mathrm{pMC}$ and increases gradually to a maximum of $96.90 \pm 0.24 \mathrm{pMC}$ in 1999 (Figure 1). The total increase in speleothem $a^{14} \mathrm{C}$ in response to the atmospheric $a^{14} \mathrm{C}$ bomb peak increase in Northern Hemisphere zone 3 of $\sim 70$ $\mathrm{pMC}$ is $8.6 \mathrm{pMC}$.

Soil $a^{14} \mathrm{CO}_{2}$ is generally lower than atmospheric $a^{14} \mathrm{CO}_{2}$, ranging from $96.20 \pm 0.16$ to $105.34 \pm 0.38 \mathrm{pMC}$ (Figure 2). Soil $p \mathrm{CO}_{2}$ is typically $<5,000$ ppm and generally increases with depth as shown in Figure 3. Soil $p \mathrm{CO}_{2}$ was lowest in March, with 2,435 ppm being highest value observed occurring at $30 \mathrm{~cm}$ depth, and the maximum observed value of 15,005 ppm observed in July at $30 \mathrm{~cm}$ depth.

Bulk SOM $a^{14} \mathrm{C}$ is shown in Table 2, and generally decreases with depth with an average value of $44 \pm 12 \mathrm{pMC}$ in the $0-5 \mathrm{~cm}$ depth interval, $27 \pm 5$ pMC in the 5-10 cm interval, and 29 \pm 16 pMC in the $10-15 \mathrm{~cm}$ interval. Soil from 10-15 cm depth was analyzed for $a^{14} \mathrm{C}$ by size fractions. Sand fractions typically each accounted for $\sim 1 / 3$ of the SOM by mass while silt and clay accounted for only $\sim 1 \%$. Coarser size fractions have lower $a^{14} \mathrm{C}$ than finer size fractions. Coarse sand has an average $a^{14} \mathrm{C}=25 \pm 3 \mathrm{pMC}$, medium sand $=38 \pm 15 \mathrm{pMC}$, fine sand $=54 \pm 16 \mathrm{pMC}$, and silt and clay $=73 \pm 20 \mathrm{pMC}$.

\subsection{Geochemical box model}

Results of the soil carbon geochemical box modeling of speleothem bomb peak records are shown in Table 3. Shown in the table are the parameters $\mathrm{P}_{j}, \mathrm{~F}_{j}, \tau_{j}$ for the best model fit, as well as the average percentage of soil $\mathrm{CO}_{2}$ derived from the annual pool $\left(\mathrm{F}_{1}\right)$ in all successful model runs. The minimum of the predicted soil $\mathrm{CO}_{2}$ age calculated from SOM parameters of all successful model runs is also shown. Plots of model results are given the 
Supplementary Material.

Modeled $\mathrm{F}_{1}$ range from $<1 \%$ to $28 \%$, with most speleothem records showing a contribution from root respiration and decomposition of organic matter of annual age accounting for $<10 \%$ of the carbon. Gib04a and CC-Bil show the largest contribution of carbon with $\tau=1$ ( $28 \%$ and $23 \%$ respectively). Model results show ER-77, Pos-stm4, and T7 speleothem carbon is derived predominately from a pool of decadal age, and Han-stm5 is a mixture of decadal and centennially aged pools. All other records showed a dominance of the flux of $\mathrm{CO}_{2}$ derived from organic carbon with a $\tau>100 \mathrm{yr}$. The minimum age of soil $\mathrm{CO}_{2}$ predicted by the all successful model runs is consistently on the order of decades or centuries, which contrasts starkly with observations of soil gas in temperate and tropical sites (Trumbore, 2000) as well as the single published measurement of soil $\mathrm{CO}_{2}$ in karst soil (Breecker et al., 2012).

\section{Discussion}

\subsection{Heshang Cave soil carbon}

Measurements of $a^{14} \mathrm{C}$ in Heshang Cave SOM and soil $\mathrm{CO}_{2}$ are both very different than published observations of $a^{14} \mathrm{C}$ in shallow tropical soils. The size fractionated SOM $a^{14} \mathrm{C}$ measurements show a trend opposite to the trend expected when separating out SOM by size fractions - typically coarse material is composed of younger material and finer fractions account for the occluded older carbon. All of the SOM $a^{14} \mathrm{C}$ measurements are much lower than is typically found in measurements of $a^{14} \mathrm{C}$ in similar shallow intervals of tropical and karst soils (e.g. 96.6 $\pm 0.6 \mathrm{pMC}$ in a Chinese mollisol (Becker- 
Heidmann et al., 1988); $109.49 \pm 0.43$ to $95.58 \pm 0.49 \mathrm{pMC}$ in a South China forest soil (Ding et al., 2010); 96.8 \pm 0.6 pMC Australian karst soil (Hobley et al., 2014)).

The very stark contrast between bulk SOM $a^{14} \mathrm{C}$ values observed at Heshang Cave ( $<58$ pMC) and SOM $a^{14} \mathrm{C}$ values observed in other similar soils (>95 pMC) raises concerns that the pretreatment methods may have affected the measurements. Soil samples from Heshang Cave were carbonate rich, with an average value of $\sim 45 \%$ carbonate by mass. It is possible that dolomite was not completely removed during pretreatment, therefore biasing SOM $a^{14} \mathrm{C}$ lower. However, the $\delta^{13} \mathrm{C}$ values of the bulk SOM samples ranged from -23.7 to $-25.9 \%$, which is typical of SOM suggesting that dolomite was successfully removed by pretreatment with $1 \mathrm{~N} \mathrm{HCl}$ overnight. Furthermore, assuming SOM samples did contain some residual dolomite with a $\delta^{13} \mathrm{C}$ of $0 \%$, and using a $\delta^{13} \mathrm{C}$ of $-27 \%$ to represent $\mathrm{SOM}$ derived of pure C3 biomass (Cerling, 1984) a simple mass balance calculation can be performed. This mass balance suggests dolomite would account for a maximum of $12 \%$ of the sample carbon, which would shift the range of $a^{14} \mathrm{C}$ for the bulk measurements from 17 - 58 pMC to at most 19 - 66 pMC. This latter range still represents very old carbon $\left(3,400\right.$ to $13,300{ }^{14} \mathrm{C}$ years).

In contrast to incomplete removal of carbonates, it is possible that the pretreatment with $1 \mathrm{~N} \mathrm{HCl}$ overnight may have digested some of the young organic carbon in the SOM. This pretreatment method is one that is a commonly employed, and similar to the methods employed in the measurements on other soils cited here. Analysis of SOM samples before and after pretreatment with $2 \mathrm{~N} \mathrm{HCl}$ for $1 \mathrm{hr}$ presented in Krull et al. (2006) show no 
statistically significant difference in $\mathrm{SOM} \delta^{13} \mathrm{C}$ or total organic carbon concentration. We therefore believe that these exceptionally low $a^{14} \mathrm{C}$ values reported here are representative of the $a^{14} \mathrm{C}$ of bulk SOM at Heshang Cave.

$a^{14} \mathrm{C}$ measurements of SOM at Heshang Cave shows that SOM at Heshang Cave is composed primarily of carbon of multi-millennial age, and the absence of bulk or size fractionated SOM measurements with post-bomb $a^{14} \mathrm{C}$ values suggests that the annual inputs of organic carbon to the soil are very low. If annual carbon inputs to soil are low, most carbon fixed in a given year must be respired in that same year, which would yield very large fluxes of $\mathrm{CO}_{2}$ with $a^{14} \mathrm{C}$ close to atmospheric, and soil $a^{14} \mathrm{CO}_{2}$ would be roughly equal to atmospheric $a^{14} \mathrm{CO}_{2}$. Indeed, observations of $a^{14} \mathrm{CO}_{2}$ in tropical soils generally suggest that they are dominated by root respiration and decomposition of decadal age SOM, which has post-bomb $a^{14} \mathrm{C}$, yielding a soil $a^{14} \mathrm{CO}_{2}$ that is higher than that of atmospheric $a^{14} \mathrm{CO}_{2}$ (e.g. Ding et al., 2010 and Trumbore, 2000). However, soil $a^{14} \mathrm{CO}_{2}$ measured at Heshang Cave is generally much lower than clean atmospheric $a^{14} \mathrm{CO}_{2}$ (Figure 2).

There are several potential sources of depleted $a^{14} \mathrm{CO}_{2}$ observed in Heshang Cave soil, both because of sampling methods and properties of the karst system. The installation of wells used to sample soil $\mathrm{CO}_{2}$ at depth causes disturbance of the soil profile and the ecosystem, which could potentially bias soil $a^{14} \mathrm{C}$, though this contribution would most likely increase decomposition of labile carbon with contemporaneous and post-bomb $a^{14} \mathrm{C}$ and therefore increase the measured $a^{14} \mathrm{CO}_{2}$. However, given the especially low $a^{14} \mathrm{C}$ of SOM and the apparent absence of decadal aged carbon, even in an undisturbed profile, a small flux of decomposition of multi-millennial aged SOM 
found at Heshang Cave could achieve the observed offset of soil $a^{14} \mathrm{CO}_{2}$ from atmospheric $a^{14} \mathrm{CO}_{2}$.

Given the very high carbonate concentration of the soil, it is also possible that some of the soil $\mathrm{CO}_{2}$ is derived from $a^{14} \mathrm{C}$-free carbonates through active carbonate dissolution and precipitation processes occurring in the soil. The open-system model of carbonate dissolution assumes continuous equilibration of soil water DIC with soil $\mathrm{CO}_{2}$, causing the incorporation of $a^{14} \mathrm{C}$-free carbon derived from dissolution of the carbonate bedrock into to soil DIC pool, including the soil $\mathrm{CO}_{2}$. Very large fluxes of non-biogenic $\mathrm{CO}_{2}$ have been observed karst terrains (Sanchez-Cañete et al., 2011), suggesting that it is possible for carbonate dissolution and precipitation processes to have an appreciable affect on the carbon isotope ratios of soil $\mathrm{CO}_{2}$ in karst terrains.

Modeling results suggest that the $\mathrm{CO}_{2}$ from which speleothem carbon in HS4 is derived predominately from decomposition of a single pool with a $\tau=136 \mathrm{yr}$. This result predicts that soil $a^{14} \mathrm{CO}_{2}$ would be $105.7 \mathrm{pMC}$ in 2010, which is essentially indistinguishable from contemporaneous atmospheric $a^{14} \mathrm{CO}_{2}$, but inconsistent with measured soil $a^{14} \mathrm{CO}_{2}$ (Figure 2). Given the dense local vegetation and absence of post-bomb $a^{14} \mathrm{C}$ in the SOM, we believe that soil $\mathrm{CO}_{2}$ at Heshang Cave is most likely derived predominately from carbon fixed during the current year and offset from contemporaneous atmospheric $a^{14} \mathrm{CO}_{2}$ by incorporation of $a^{14} \mathrm{C}$-free bedrock derived carbon in the soil DIC pool due open-system carbonate dissolution and carbonate preciptation. However, the measurements made in this study are insufficient to confirm this hypothesis, and suggest that soil carbon dynamics are very complicated at this site, and perhaps across karst sites in 
general. The unusual soil $a^{14} \mathrm{C}$ measurements presented in this manuscript highlight the need for further investigations of soil carbon dynamics in karst sites to determine if they are consistently storing large quantities of very old SOM and how SOM decomposition at these sites responds to global climate change. Furthermore the disagreement between the modeled soil Heshang Cave $a^{14} \mathrm{CO}_{2}$ based on the HS4 speleothem $a^{14} \mathrm{C}$ bomb peak profile and observed Heshang Cave $a^{14} \mathrm{CO}_{2}$ suggest that the conceptional model of the sources of speleothem carbon is in need of revision.

\subsection{The sources of speleothem carbon}

Modeling results suggest that $\mathrm{CO}_{2}$ derived from root respiration and decomposition of organic matter with $\tau<1$ year does not represent a significant portion of speleothem carbon, which is similar to the results of similar studies. Genty and Massault (1997) referred to the soil $a^{14} \mathrm{CO}_{2}$ measurements of Dörr and Münnich (1986) which suggested that under forested soil in Germany decomposition of SOM with $\tau=100$ years composes $25 \%$ of soil $\mathrm{CO}_{2}$ flux in the summer and $75 \%$ of the flux in the winter. Under the assumption that the majority of infiltration in temperate settings occurs during the winter months, when photosynthesis is at a minimum, previous studies have argued that model parameters that suggest that speleothem carbon is derived from soil $\mathrm{CO}_{2}$ that is primarily derived from decomposition of old SOM are in good agreement with observations of winter soil $a^{14} \mathrm{CO}_{2}$.

However, even if this assumption is accurate for sites where the growing season is out of phase with the rainy season, it is certainly not the case in tropical and sub-tropical sites with monsoon climates where the growing season and rainy season are in phase. Moreover, the assumption that 
speleothem carbon is predominantly derived from winter soil $\mathrm{CO}_{2}$ is difficult to reconcile even in temperate sites because of the particularly low soil $p \mathrm{CO}_{2}$ in temperate sites during the winter. Dörr and Münnich (1986) measured winter $p \mathrm{CO}_{2}$ in the forested soil of $<3,000 \mathrm{ppm}$, and Tegen and Dorr (1996) typically observed concentrations of $<2,000 \mathrm{ppm}$ in German forest during cold seasons. Measurements of soil $p \mathrm{CO}_{2}$ at Grotto di Ernesto also showed values of $\sim 2,000 \mathrm{ppm}$ in winter.

Modeling drip water carbonate chemistry using these observed low soil $p \mathrm{CO}_{2}$ values has proved difficult to reconcile with observed drip water $\mathrm{Ca}^{2+}$ concentrations. For example, Fohlmeister et al. (2011b) used a carbonate dissolution model to calculate Grotto di Ernesto ER-G1 drip water carbon isotope ratios and $\mathrm{Ca}^{2+}$ concentrations using the annual average soil $p \mathrm{CO}_{2}$ observed above Grotto di Ernesto of 4,000 ppm. When the model was able to accurately reproduce drip water $a^{14} \mathrm{C}$, it underestimated the $\mathrm{Ca}^{2+}$ concentration by a factor of $\sim 2$. Fohlmeister et al. (2011b) suggested that the discrepancy could be due to the longer time necessary to establish equilibrium between soil water and soil gas for carbon isotopes than $\mathrm{Ca}^{2+}$, however, another possibility is that the initial $p \mathrm{CO}_{2}$ used in the model was too low. In fact, to attain typically observed drip water $\mathrm{Ca}^{2+}$ concentrations of $\sim 2$ $\mathrm{mmol} / \mathrm{L}$ via completely open-system dissolution requires an initial $p \mathrm{CO}_{2}$ of 10,000 ppm, while completely closed-system dissolution requires an initial $p \mathrm{CO}_{2}$ of 50,000 ppm (Hansen et al., 2013).

When Fohlmeister et al. (2011b) forced their model to fit observed drip water $\mathrm{Ca}^{2+}$ values, calculated drip water $a^{14} \mathrm{C}$ was higher than observed drip water $a^{14} \mathrm{C}$ by $6.5 \mathrm{pMC}$. The initial value used for the soil $a^{14} \mathrm{CO}_{2}$ was based 
on the soil carbon parameters modeled from a bomb peak record from ER77 using the moving average approach to estimate soil $a^{14} \mathrm{CO}_{2}$ (Fohlmeister et al., 2011a). The best fit to ER-77 using the model described in this manuscript suggests that the a lower initial $a^{14} \mathrm{CO}_{2}$ may be appropriate for the carbon source for ER-77, which could potentially improve the performance of the Fohlmeister et al. (2011b) model in estimating drip water geochemistry.

Given the low $p \mathrm{CO}_{2}$ observed in shallow karst soils, and the disagreement between observations of soil $a^{14} \mathrm{CO}_{2}$ and the $a^{14} \mathrm{CO}_{2}$ necessary to reproduce the speleothem bomb peak records as predicted by all modeling approaches attempted, we suggest that in many karst systems $\mathrm{CO}_{2}$ in the soil zone is not the dominant source of speleothem carbon. The near absence of root respiration signal in speleothem carbon suggests the possibility of a source of $\mathrm{CO}_{2}$ that is removed from the soil zone, where decomposition of aged SOM occurs in isolation.

Very high vadose zone $p \mathrm{CO}_{2}$ has long been known to occur in both carbonate and carbonate-free settings, (e.g. Bacon and Keller, 1998; Murphy et al., 1992; Keller, 1991; Keller and Bacon, 1998; Wood and Petraitis, 1984; Wood et al., 1993; Hendry et al., 1993; Hendry and Wassenaar, 2005; and Lawrence et al., 2000), and isotopic evidence suggest that microbial respiration of organic material is the dominant source of subterranean $\mathrm{CO}_{2}$. Most relevant to karst settings, Benavente et al. (2010) measured soil and vadose zone $p \mathrm{CO}_{2}$ and $\delta^{13} \mathrm{C}$ in a Mediterranian karst. Benavente et al. (2010) measured $p \mathrm{CO}_{2}$ of $<2,000 \mathrm{ppm}$ with a $\delta^{13} \mathrm{C}$ of -11.2 to $-20.6 \%$ in the soil, and $p \mathrm{CO}_{2}$ of $>20,000 \mathrm{ppm}$ in wells at depths of $>10 \mathrm{~m}$, with a $\delta^{13} \mathrm{C}$ ranging 
from -19.7 to $-22.1 \%$, suggesting the $\mathrm{CO}_{2}$ was derived from an organic matter source. Peyraube et al. (2013) estimated vadose zone $p \mathrm{CO}_{2}$ based on carbon isotopic evidence in cave drip water and $\mathrm{CO}_{2}$, and suggests vadose zone $p \mathrm{CO}_{2}$ values of $4.4 \%(44,000 \mathrm{ppm})$ in winter and $10 \%$ in summer with $\delta^{13} \mathrm{C}$ values of $-22.31 \%$ and $-24.20 \%$, which is in good agreement with the observations presented by Benavente et al. (2010). Additionally a study of the sources of cave $\mathrm{CO}_{2}$ by Breecker et al. (2012) also hypothesized that the majority of cave $\mathrm{CO}_{2}$ is advected from a deep biogenic source, and numerous studies have suggested that generation of subterranean $\mathrm{CO}_{2}$ is an important, and possibly necessary, driver of carbonate dissolution and karst development (e.g. Wood, 1985; Atkinson, 1977; Gabrovšek et al., 2000; and Gulley et al., 2014)

\subsection{Implications for interpretation of speleothem carbon isotope records}

The apparent stability of the offset between speleothem $a^{14} \mathrm{C}$ and contemporaneous atmospheric $a^{14} \mathrm{CO}_{2}$, commonly referred to as the dead carbon proportion (DCP), in some speleothems observed across major climate transitions has been both the most promising and puzzling result of attempts to produce speleothem-based records of atmospheric $a^{14} \mathrm{C}$. Most exceptionally in the Hulu Cave speleothem, H82, DCP showed no response throughout the Younger Dryas despite the changes in summer monsoon intensity inferred from speleothem $\delta^{18} \mathrm{O}$, and vegetation changes inferred by pollen evidence (Southon et al., 2012). The hypothesis that some speleothems are formed predominately from $\mathrm{CO}_{2}$ in the vadose zone derived from microbial decomposition of aged organic matter could potentially begin to explain the apparent stability of DCP in speleothems through major climate transitions. Changes 
in temperature and moisture conditions at the surface would be expected to induce relatively less variability in the conditions of the deep vadose zone. If speleothem carbon is derived predominately from decomposition of SOM in the insulated subsurface, this process would act to filter out both abrupt changes in global atmospheric $a^{14} \mathrm{C}$, like the twentieth century atmospheric $a^{14} \mathrm{C}$ bomb peak, and short-term changes in surface soil dynamics.

Changes in hydrology appear to be the most important driver of speleothem DCP (Griffiths et al., 2012 and Noronha et al., 2014), with a working hypothesis that higher precipitation increases soil moisture, therefore limiting $\mathrm{CO}_{2}$ diffusion and open-system dissolution, and leading to a higher proportion of carbon derived from the $a^{14} \mathrm{C}$-free bedrock. In a system where most drip water DIC is acquired during open-system dissolution occurring at depth in the vadose zone, open-system dissolution, which relies on the assumption of a functionally infinite supply of $\mathrm{CO}_{2}$ could only occur when voids in the bedrock are filled with more gas than water. During periods of higher infiltration this condition would be met less often, and closed-system dissolution would dominate, leading to higher speleothem DCP during periods of higher recharge.

This smoothing of surface changes in speleothem $a^{14} \mathrm{C}$, driven by dominance of carbon derived from decomposition of aged SOM in the deep vadose zone over root respiration in the shallow soil zone, suggests that SOM derived changes in speleothem $\delta^{13} \mathrm{C}$ records must be similarly muted. Complicated organic carbon cycling in karst terrains suggests that shifts between vegetation using C3 and C4 photosynthetic pathways will be muted and lagged in both organic and inorganic carbon isotope records. In addition to the im- 
portance of interpreting speleothem carbon isotope records in light of these temporal lags and the attenuation of surface signals, there exists a growing body of research developing paleoenvironmental proxies using organic matter preserved in speleothem calcite and organic-mineral associations (e.g. Xie et al., 2003; Blyth et al., 2008; Huang et al., 2008; Perrette et al., 2008; Li et al., 2011; Hartland et al., 2012; and Blyth et al., 2013) which should be interpreted in light of the complicated carbon cycling and unique transport mechanisms occurring in karst systems.

\section{Conclusion}

We have developed an improved model of the sources of speleothem carbon which allows prediction the SOM age distribution required to produce the shape of the speleothem twentieth century $a^{14} \mathrm{C}$ bomb peak. The results of this modeling work confirm the results of previous studies, which suggest that a large flux of $\mathrm{CO}_{2}$ derived from organic material with turnover times on the order of centuries is necessary to produce the observed speleothem $a^{14} \mathrm{C}$ bomb peak. This result suggests that soil $\mathrm{CO}_{2}$ is not the main source of speleothem carbon, and therefore we argue that $\mathrm{CO}_{2}$ produced by microbial decomposition of SOM in the deep vadose zone is likely to be the main source of speleothem carbon.

Our observations of soil carbon at Heshang Cave, China and a review of the literature indicates that karst systems are unique ecosystems where organic matter undergoes complicated alterations and transformations, which currently have received relatively little attention. Continued study of carbon cycling in karst settings is crucially important to improve our understanding 
of the role of karst soils in the global carbon-climate feedback cycle and to improve interpretation of speleothem-based paleoenvironmental records.

\section{Acknowledgements}

This research was supported by NSF AGS-0903101 to KRJ, NSF EAPSI1107922 to ALN, and NSFC 41072262 to HCY. We thank Xioamei Xu, Claudia Czimczik, and Guaciera dos Santos for laboratory assistance and helpful conversations, the guest editors of this special issue, Jens Fohlmeister, and one anonymous reviewer for their comments which significantly improved this manuscript. The model Matlab code is available at https://github.com/anoronha.

Atkinson, T. C., 1977. Carbon dioxide in the atmosphere of the unsaturated zone: an important control of groundwater hardness in limestones. Journal of Hydrology 35, 111-123.

Bacon, D. H., Keller, C. K., 1998. Carbon dioxide respiration in the deep vadose zone: Implications for groundwater age dating. Water Resources Research 34 (11), 3069-3077.

Baker, A., Asrat, A., Fairchild, I. J., Leng, M. J., Wynn, P. M., Bryant, C. L., Genty, D., Umer, M., 2007. Analysis of the climate signal contained within $\delta^{18} \mathrm{O}$ and growth rate parameters in two Ethiopian stalagmites. Geochimica et Cosmochimica Acta 71 (12), 2975-2988.

Becker-Heidmann, P., Liang-wu, L., Scharpenseel, H.-W., 1988. Radiocarbon Dating of Organic Matter Fractions of a Chinese Mollisol. Zeitschrift für Pflanzenernährung und Bodenkunde 151 (1), 37-39. 
Benavente, J., Vadillo, I., Carrasco, F., Soler, a., Liñán, C., Moral, F., 2010. Air Carbon Dioxide Contents in the Vadose Zone of a Mediterranean Karst. Vadose Zone Journal 9 (1), 126.

Blyth, A. J., Baker, A., Collins, M. J., Penkman, K. E., Gilmour, M. a., Moss, J. S., Genty, D., Drysdale, R. N., 2008. Molecular organic matter in speleothems and its potential as an environmental proxy. Quaternary Science Reviews 27 (9-10), 905-921.

Blyth, A. J., Smith, C. I., Drysdale, R. N., 2013. A new perspective on the $\delta^{13} \mathrm{C}$ signal preserved in speleothems using LC-IRMS analysis of bulk organic matter and compound specific stable isotope analysis. Quaternary Science Reviews 75, 143-149.

Breecker, D. O., Payne, A. E., Quade, J., Banner, J. L., Ball, C. E., Meyer, K. W., Cowan, B. D., 2012. The sources and sinks of $\mathrm{CO}_{2}$ in caves under mixed woodland and grassland vegetation. Geochimica et Cosmochimica Acta 96, 230-246.

Cerling, T. E., 1984. The stable isotopic composition of modern soil carbonate and its relationship to climate. Earth and Planetary Science Letters 71 (2), 229-240.

Ding, P., Shen, C. D., Wang, N., Yi, W. X., Ding, X. F., Fu, D. P., Liu, K. X., Zhou, L. P., 2010. Turnover Rate Of Soil Organic Matter And Origin Of Soil ${ }^{14} \mathrm{CO}_{2}$ In Deep Soil From A Subtropical Forest In Dinghushan Biosphere Reserve, South China. Radiocarbon 52 (2), 1422-1434. 
Dörr, H., Münnich, K. O., 1986. Annual variations of the ${ }^{14} \mathrm{C}$ Content of Soil $\mathrm{CO}_{2}$. Radiocarbon 28 (2A), 338-345.

Dreybrodt, W., 2008. Evolution of the isotopic composition of carbon and oxygen in a calcite precipitating $\mathrm{H}_{2} \mathrm{O}-\mathrm{CO}_{2}-\mathrm{CaCO}_{3}$ solution and the related isotopic composition of calcite in stalagmites. Geochimica et Cosmochimica Acta 72 (19), 4712-4724.

English, N. B., McDowell, N. G., Allen, C. D., Mora, C., 2011. The effects of $\alpha$-cellulose extraction and blue-stain fungus on retrospective studies of carbon and oxygen isotope variation in live and dead trees. Rapid Communications in Mass Spectrometry 25 (20), 3083-3090.

Fairchild, I. J., Smith, C. L., Baker, A., Fuller, L., Spötl, C., Mattey, D. P., McDermott, F., 2006. Modification and preservation of environmental signals in speleothems. Earth-Science Reviews 75 (1-4), 105-153.

Fohlmeister, J., Kromer, B., Mangini, A., 2011a. The Influence Of Soil Organic Matter Age Spectrum On The Reconstruction Of Atmospheric ${ }^{14} \mathrm{C}$ Levels Via Stalagmites. Radiocarbon 53 (1), 99-115.

Fohlmeister, J., Scholz, D., Kromer, B., Mangini, A., 2011b. Modelling carbon isotopes of carbonates in cave drip water. Geochimica et Cosmochimica Acta 75 (18), 5219-5228.

Fohlmeister, J., Schröder-Ritzrau, A., Spötl, C., 2010. The Influences Of Hydrology On The Radiogenic And Stable Carbon Isotope Composition Of Cave Drip Water, Grotta Di Ernesto (Italy). Radiocarbon 52 (4), 15291544 . 
Frisia, S., Borsato, A., 2010. Chapter 6: Karst. In: Alonso-Zarza, A. M., Tanner, L. H. (Eds.), Carbonates in Continental Settings: Facies, Environments, and Processes. Vol. 61. Elsevier, pp. 61, 269-318.

Frisia, S., Fairchild, I. J., Fohlmeister, J., Miorandi, R., Spötl, C., Borsato, A., 2011. Carbon mass-balance modelling and carbon isotope exchange processes in dynamic caves. Geochimica et Cosmochimica Acta 75 (2), $380-400$.

Gabrovšek, F., Menne, B., Dreybrodt, W., 2000. A model of early evolution of karst conduits affected by subterranean $\mathrm{CO}_{2}$ sources. Environmental Geology 39 (6), 531-543.

Gaudinski, J. B., Trumbore, S. E., Davidson, E. A., Zheng, S., Eric, A., 2000. Soil carbon cycling in a temperate forest: radiocarbon-based estimates of residence times, sequestration rates and partitioning of fluxes. Biogeochemistry 51, 33-69.

Genty, D., Baker, A., Massault, M., Proctor, C., Gilmour, M., Pons-Branchu, E., Hamelin, B., 2001. Dead carbon in stalagmites: carbonate bedrock paleodissolution vs. ageing of soil organic matter. Implications for ${ }^{13} \mathrm{C}$ variations in speleothems. Geochimica et Cosmochimica Acta 65 (20), 34433457.

Genty, D., Massault, M., 1997. Bomb ${ }^{14} \mathrm{C}$ Recorded in laminated Speleothems: Calculations of Dead Carbon Proportion. Radiocarbon 39 (1), 33-48. 
Genty, D., Massault, M., 1999. Carbon transfer dynamics from bomb- ${ }^{14} \mathrm{C}$ and $\delta^{13} \mathrm{C}$ time series of a laminated stalagmite from SW France - modelling and comparison with other stalagmite records. Geochimica et Cosmochimica Acta 63 (10), 1537-1548.

Genty, D., Vokal, B., Obelić, B., 1998. Bomb ${ }^{14} \mathrm{C}$ time history recorded in two modern stalagmites - importance for soil organic matter dynamics and bomb ${ }^{14} \mathrm{C}$ distribution over continents. Earth and Planetary Science Letters 160, 795-809.

Griffiths, M., Fohlmeister, J., Drysdale, R., Hua, Q., Johnson, K. R., Hellstrom, J., Gagan, M., Zhao, J.-X., 2012. Hydrological control of the dead carbon fraction in a Holocene tropical speleothem. Quaternary Geochronology $14,81-93$.

Gulley, J., Martin, J., Moore, P., 2014. Vadose $\mathrm{CO}_{2}$ gas drives dissolution at water tables in eogenetic karst aquifers more than mixing dissolution. Earth Surface Processes and Landforms 39 (13), 1833-1846.

Hansen, M., Dreybrodt, W., Scholz, D., 2013. Chemical evolution of dissolved inorganic carbon species flowing in thin water films and its implications for (rapid) degassing of $\mathrm{CO}_{2}$ during speleothem growth. Geochimica et Cosmochimica Acta 107, 242-251.

Hartland, A., Fairchild, I. J., Lead, J. R., Borsato, A., Baker, A., Frisia, S., Baalousha, M., 2012. From soil to cave: Transport of trace metals by natural organic matter in karst dripwaters. Chemical Geology 304-305, $68-82$. 
Hendry, M. J., Lawrence, J. R., Zanyk, B. N., Kirkland, R., 1993. Microbial Production of $\mathrm{CO}_{2}$ in Unsaturated Geologic Media in a Geologic Media in a Mesoscale Model. Water Resources Research 29 (4), 973-984.

Hendry, M. J., Wassenaar, L. I., 2005. Origin and migration of dissolved organic carbon fractions in a clay-rich aquitard: ${ }^{14} \mathrm{C}$ and $\delta^{13} \mathrm{C}$ evidence. Water Resources Research 41 (2).

Hendy, C., 1971. The isotopic geochemistry of speleothems - I. The calculation of the effects of different modes of formation on the isotopic composition of speleothems and their applicability as palaeoclimatic indicators. Geochimica et Cosmochimica Acta 35 (8), 801-824.

Hobley, E., Willgoose, G. R., Frisia, S., Jacobsen, G., 2014. Stability and storage of soil organic carbon in a heavy-textured Karst soil from southeastern Australia. Soil Research 52, 476-482.

Hu, C., Henderson, G., Huang, J., Chen, Z., Johnson, K. R., 2008a. Report of a three-year monitoring programme at Heshang Cave, Central China. International Journal of Speleology 37 (3), 143-151.

Hu, C., Henderson, G. M., Huang, J., Xie, S., Sun, Y., Johnson, K. R., 2008b. Quantification of Holocene Asian monsoon rainfall from spatially separated cave records. Earth and Planetary Science Letters 266 (3-4), 221-232.

Hua, Q., Barbetti, M., Rakowski, A., 2013. Atmospheric radiocarbon for the period 1950-2010. Radiocarbon 55 (4), 2059-2072. 
Huang, X., Cui, J., Pu, Y., Huang, J., Blyth, A. J., 2008. Identifying "free" and "bound" lipid fractions in stalagmite samples: An example from Heshang Cave, Southern China. Applied Geochemistry 23 (9), 2589-2595.

Johnson, K. R., Hu, C., Belshaw, N., Henderson, G., 2006. Seasonal traceelement and stable-isotope variations in a Chinese speleothem: The potential for high-resolution paleomonsoon reconstruction. Earth and Planetary Science Letters 244 (1-2), 394-407.

Keller, C. K., 1991. Hydrogeochemistry of a Clayey Till - Sources of $\mathrm{CO}_{2}$. Water Resources Research 27 (10), 2555-2564.

Keller, C. K., Bacon, D. H., 1998. Soil respiration and georespiration distinguished by transport analyses of vadose $\mathrm{CO}_{2},{ }^{13} \mathrm{CO}_{2}$, and ${ }^{14} \mathrm{CO}_{2}$. Global Biogeochemical Cycles 12 (2), 361-372.

Krull, E., Bestland, E., Gates, W., Ding, P., Shen, C., Wang, N., Yi, W., 2006. Soil organic matter decomposition and turnover in a tropical Ultisol: evidence from $\delta^{13} \mathrm{C}, \delta^{15} \mathrm{~N}$ and geochemistry. Radiocarbon 44 (1), 1422 1434 .

Lawrence, J., Hendry, M., Wassenaar, L. I., Germida, J., Wolfaardt, G., Fortin, N., Greer, C., 2000. Distribution and Biogeochemical Importance of Bacterial Populations in a Thick Clay-Rich Aquitard System. Microbial Ecology 40 (4), 273-291.

Levin, I., Kromer, B., Hammer, S., 2013. Atmospheric $\Delta^{14} \mathrm{CO}_{2}$ trend in Western European background air from 2000 to 2012. Tellus B (65), 1-7. 
Li, X., Wang, C., Huang, J., Hu, C., Xie, S., 2011. Seasonal variation of fatty acids from drip water in Heshang Cave, central China. Applied Geochemistry 26 (3), 341-347.

Liu, Y.-H., Henderson, G. M., Hu, C.-Y., Mason, a. J., Charnley, N., Johnson, K. R., Xie, S.-C., 2013. Links between the East Asian monsoon and North Atlantic climate during the 8,200 year event. Nature Geoscience $6(2), 117-120$.

Mattey, D. P., Lowry, D., Duffet, J., Fisher, R., Hodge, E., Frisia, S., 2008. A 53year seasonally resolved oxygen and carbon isotope record from a modern Gibraltar speleothem: Reconstructed drip water and relationship to local precipitation. Earth and Planetary Science Letters 269 (1-2), 80-95.

Mickler, P. J., Banner, J. L., Stern, L., Asmerom, Y., Edwards, R. L., Ito, E., 2004. Stable isotope variations in modern tropical speleothems: Evaluating equilibrium vs. kinetic isotope effects. Geochimica et Cosmochimica Acta 68 (21), 4381-4393.

Murphy, E. M., Schramke, J. A., Fredrickson, J. K., Bledsoe, H. W., Francis, A. J., Sklarew, D., Linehan, J. C., 1992. The influence of microbial activity and sedimentary organic carbon on the isotope geochemistry of the Middendorf aquifer. Water Resources Research 28 (3), 723-740.

Noronha, A. L., Johnson, K. R., Hu, C., Ruan, J., Southon, J. R., Ferguson, J. E., 2014. Assessing influences on speleothem dead carbon variability over the Holocene: Implications for speleothem-based radiocarbon calibration. Earth and Planetary Science Letters 394, 20-29. 
Perrette, Y., Poulenard, J., Saber, A.-I., Fanget, B., Guittonneau, S., Ghaleb, B., Garaudee, S., 2008. Polycyclic Aromatic Hydrocarbons in stalagmites: Occurrence and use for analyzing past environments. Chemical Geology $251(1-4), 67-76$.

Peyraube, N., Lastennet, R., Denis, a., Malaurent, P., 2013. Estimation of epikarst air $p \mathrm{CO}_{2}$ using measurements of water $\delta^{13} C_{T D I C}$, cave air $p \mathrm{CO}_{2}$ and $\delta^{13} \mathrm{CO}_{2}$. Geochimica et Cosmochimica Acta 118, 1-17.

Reimer, P. J., Bard, E., Bayliss, A., Beck, J. W., Blackwell, P. G., Ramsey, C. B., Buck, C. E., Cheng, H., Edwards, R. L., Friedrich, M., Grootes, P. M., Guilderson, T. P., Haflidason, H., Hajdas, I., Hatte, C., Heaton, T. J., Hoffmann, D. L., Hogg, A. G., Hughen, K. A., Kaiser, K. F., Kromer, B., Manning, S. W., Niu, M., Reimer, R. W., Richards, D. A., Scott, E. M., Southon, J. R., Staff, R., Turney, C. S. M., van der Plicht, J., 2013. IntCal13 and Marine13 Radiocarbon Age Calibration Curves 0-50,000 years cal BP. Radiocarbon 55 (4), 1869-1887.

Rudzka-Phillips, D., McDermott, F., Jackson, a., Fleitmann, D., 2013. Inverse modelling of the ${ }^{14} \mathrm{C}$ bomb pulse in stalagmites to constrain the dynamics of soil carbon cycling at selected European cave sites. Geochimica et Cosmochimica Acta 112, 32-51.

Saliege, J., Fontes, J., 1984. Essai de détermination expérimentale du fractionnement des isotopes ${ }^{13} \mathrm{C}$ et ${ }^{14} \mathrm{C}$ du carbone au cours de processus naturels. The International Journal of Applied Radiation and Isotopes 35 (1), 55-62. 
Sanchez-Cañete, E. P., Serrano-Ortiz, P., Kowalski, A. S., Oyonarte, C., Domingo, F., 2011. Subterranean $\mathrm{CO}_{2}$ ventilation and its role in the net ecosystem carbon balance of a karstic shrubland. Geophysical Research Letters 38 (9).

Santos, G., Moore, R. B., Southon, J. R., Griffin, S., Hinger, E., Zhang, D., 2007. AMS ${ }^{14} \mathrm{C}$ Sample preparation at the KCCAMS/UCI Facility: Status Report and Performance of Small Samples. Radiocarbon 49 (2), 255-269.

Six, J., Jastrow, J. D., 2002. Organic Matter Turnover. In: Encyclopedia of Soil Science. pp. 936-942.

Smith, C. L., Fairchild, I. J., Spötl, C., Frisia, S., Borsato, A., Moreton, S. G., Wynn, P. M., 2009. Chronology building using objective identification of annual signals in trace element profiles of stalagmites. Quaternary Geochronology 4 (1), 11-21.

Southon, J. R., 2011. Are the Fractionation Corrections Correct: Are the isotopic shifts for ${ }^{14} \mathrm{C} /{ }^{12} \mathrm{C}$ ratios in physical processes and chemical reactions really twice those for ${ }^{13} \mathrm{C} /{ }^{12} \mathrm{C}$ ? Radiocarbon 53 (4), 691-704.

Southon, J. R., Magana, A. L., 2010. A Comparison Of Cellulose Extraction And ABA Pretreatment Methods For AMS ${ }^{14} \mathrm{C}$ Dating Of Ancient Wood. Radiocarbon 52 (3), 1371-1379.

Southon, J. R., Noronha, A. L., Cheng, H., Edwards, R. L., Wang, Y., 2012. A high-resolution record of atmospheric ${ }^{14} \mathrm{C}$ based on Hulu Cave speleothem H82. Quaternary Science Reviews 33, 32-41. 
Spötl, C., Fairchild, I. J., Tooth, A. F., 2005. Cave air control on dripwater geochemistry, Obir Caves (Austria): Implications for speleothem deposition in dynamically ventilated caves. Geochimica et Cosmochimica Acta 69 (10), 2451-2468.

Stuiver, M., Polach, H. A., 1977. Reporting of C-14 data. Radiocarbon 19 (3), $355-363$.

Sundqvist, H. S., Holmgren, K., Fohlmeister, J., Zhang, Q., Matthews, M. B., Spötl, C., Körnich, H., 2013. Evidence of a large cooling between 1690 and 1740 AD in southern Africa. Scientific Reports 3, 1767.

Tegen, I., Dorr, H., 1996. ${ }^{14} \mathrm{C}$ measurements of soil organic matter, soil $\mathrm{CO}_{2}$ and dissolved organic carbon (1987-1992). Radiocarbon 38 (2), 247-251.

Trumbore, S. E., 1993. Comparison of carbon dynamics in tropical and temperate soils using radiocarbon measurements. Global Biogeochemical Cycles 7 (2), 275-290.

Trumbore, S. E., 2000. Age of soil organic matter and soil respiration: Radiocarbon constraints on belowground $\mathrm{C}$ dynamics. Ecological Applications 10 (2), 399-411.

Wood, B. D., Keller, C. K., Johnston, D. L., 1993. In Situ Measurement of Microbial Activity and Controls on Microbial $\mathrm{CO}_{2}$ Production in the Unsaturated Zone. Water Resources Research 29 (3).

Wood, W. W., 1985. Origin of caves and other solution openings in the unsaturated (vadose) zone of carbonate rocks: A model. Geology 13, 822824. 
${ }_{797}$ Wood, W. W., Petraitis, M. J., 1984. Origin and Distribution of Carbon

Dioxide in the Unsaturated Zone of the Southern High Plains of Texas. Water Resources Research 20 (9), 1193-1208.

Xie, S., Yi, Y., Huang, J., Hu, C., Cai, Y., Collins, M., Baker, A., 2003. Lipid distribution in a subtropical southern China stalagmite as a record of soil ecosystem response to paleoclimate change. Quaternary Research 60, 340-347.

Xu, X., Trumbore, S. E., Zheng, S., Southon, J. R., McDuffee, K. E., Luttgen, M., Liu, J. C., 2007. Modifying a sealed tube zinc reduction method for preparation of AMS graphite targets: Reducing background and attaining high precision. Nuclear Instruments and Methods in Physics Research Section B: Beam Interactions with Materials and Atoms 259 (1), 320-329. 


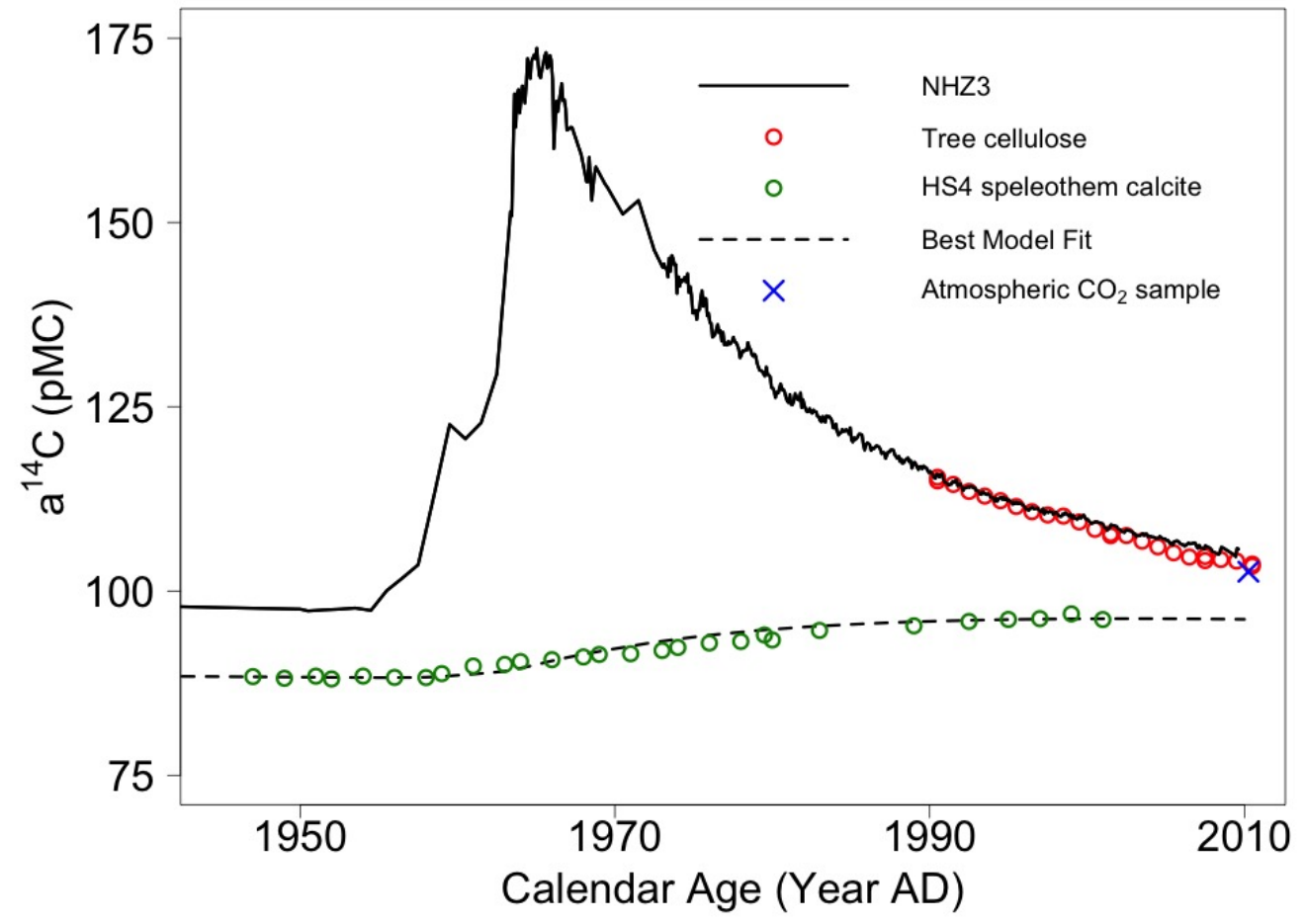

Figure 1: Speleothem HS4 twentieth century $a^{14} \mathrm{C}$ (green) plotted with Northern Hemisphere zone 3 Hua et al. (2013) regional atmospheric $a^{14} \mathrm{C}$ record (black), and results of local atmospheric $a^{14} \mathrm{CO}_{2}$ at Heshang Cave based on tree ring reconstruction (red), and a single atmospheric $a^{14} \mathrm{CO}_{2}$ measurement (blue). Best model fit shown in dashed line (black). 


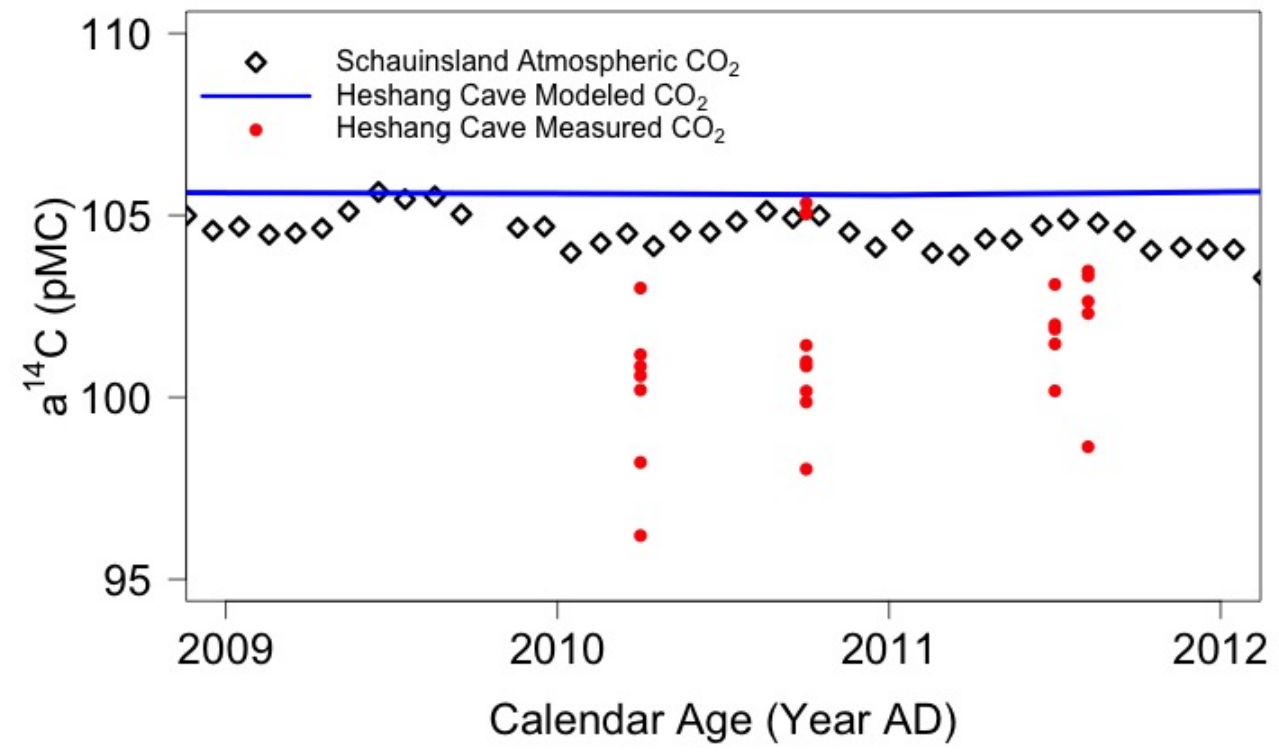

Figure 2: Observed atmospheric $a^{14} \mathrm{CO}_{2}$ in Schauinsland, Germany (Levin et al., 2013) with observed and inversely modeled Heshang Cave soil $a^{14} \mathrm{CO}_{2}$. 


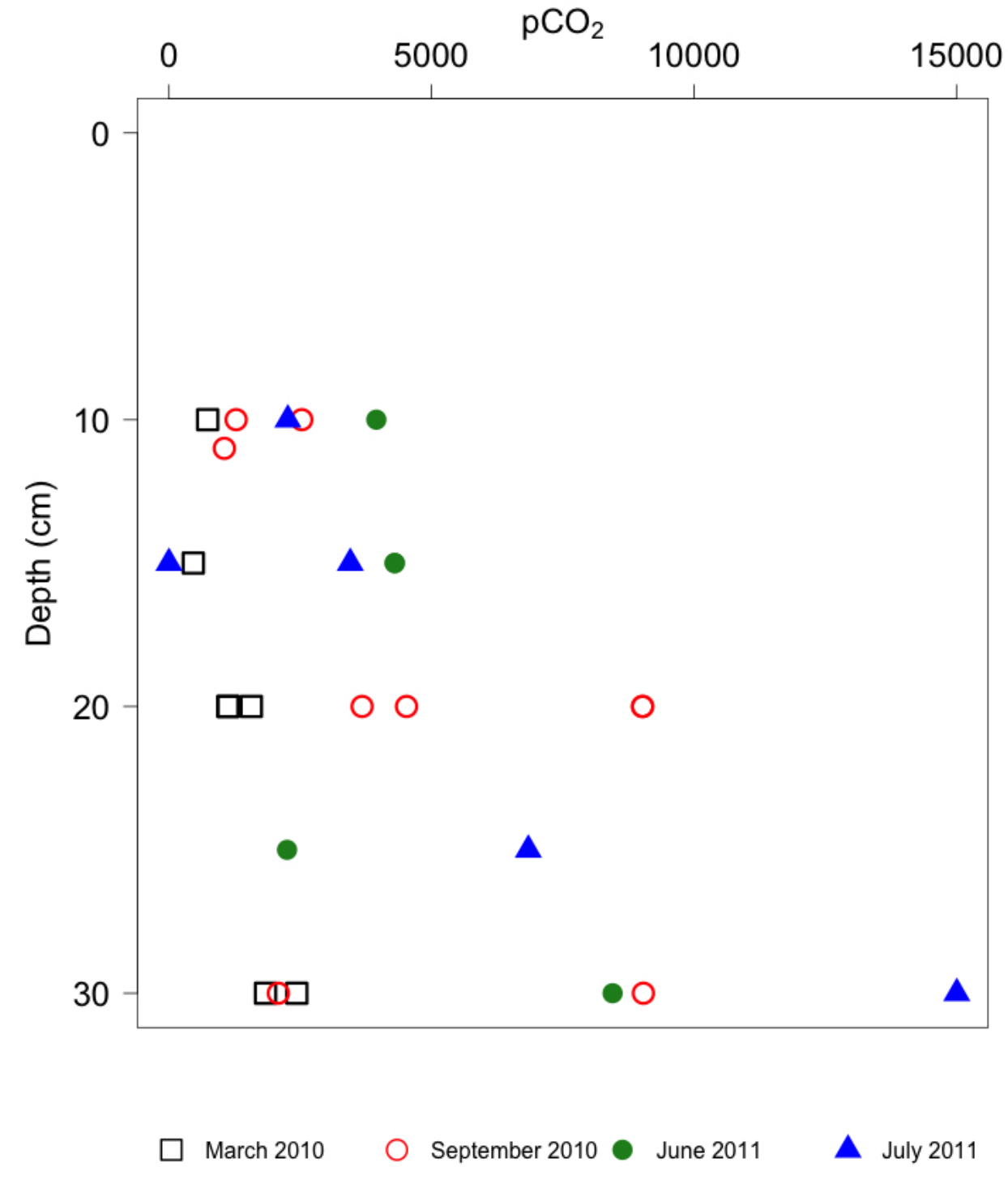

Figure 3: Heshang Cave soil $p \mathrm{CO}_{2}$ by depth 

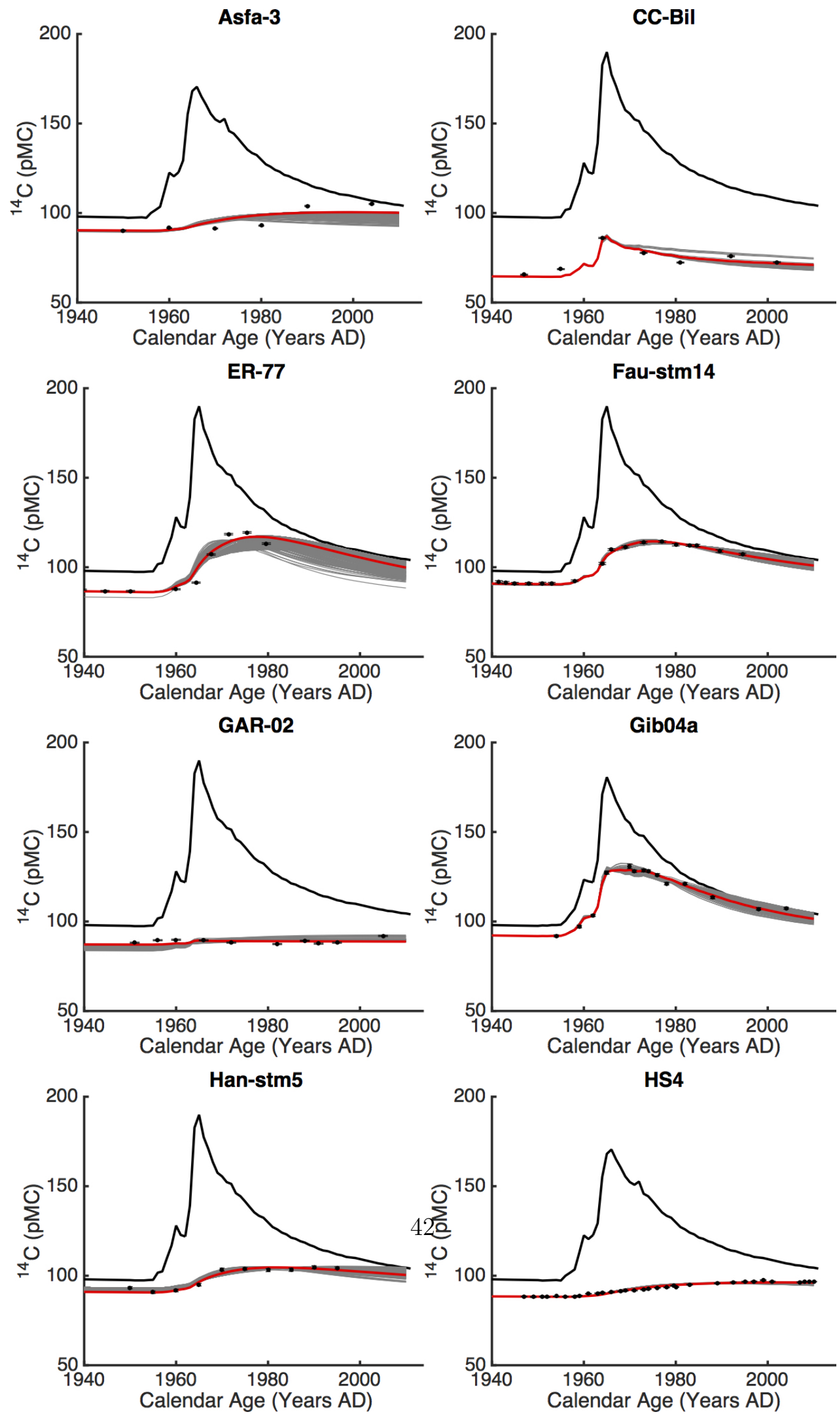

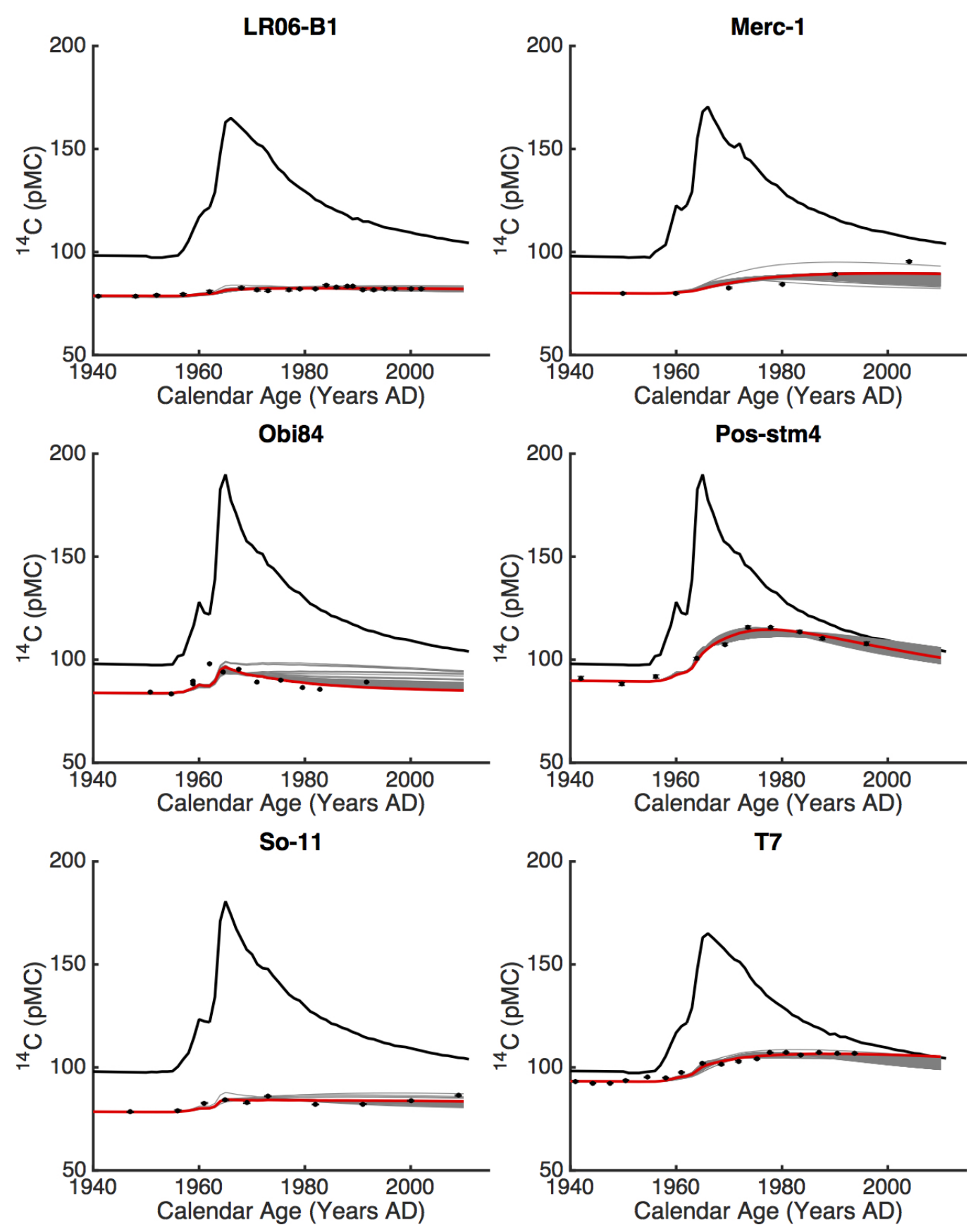

Figure 5: Supplemental Figure: Speleothem bomb peak records (black points) referred to in this manuscript plotted with their regional atmospheric $a^{14} \mathrm{C}$ curves (Hua et al., 2013) (black line), and the results of all successful model runs of the geochemical box model described in the text (grey lines). The best48odel fit is highlighted (red lines). 